\title{
Multiple Resistance Phenotypes to Lettuce mosaic virus Among Arabidopsis thaliana Accessions
}

\author{
Frédéric Revers, Thomas Guiraud, Marie-Christine Houvenaghel, Thierry Mauduit, Olivier Le Gall, \\ and Thierry Candresse
}

UMR GDPP, IBVM-INRA, BP 81, 33883 Villenave d'Ornon Cedex, France

Submitted 28 October 2002. Accepted 31 January 2003.

\begin{abstract}
With the aim to characterize plant and viral factors involved in the molecular interactions between plants and potyviruses, a Lettuce mosaic virus (LMV)-Arabidopsis thaliana pathosystem was developed. Screening of Arabidopsis accessions with LMV isolates indicated the existence of a large variability in the outcome of the interaction, allowing the classification of Arabidopsis accessions into seven susceptibility groups. Using a reverse genetic approach, the genome-linked protein of LMV, a multifunctional protein shown to be involved in viral genome amplification and movement of potyviruses, was established as the viral determinant responsible for the ability to overcome the resistance of the Niederzenz accession to LMV-0. Preliminary genetic analyses from $\mathrm{F} 2$ and recombinant inbred lines available between susceptible and resistant Arabidopsis accessions revealed the existence of at least three resistance phenotypes to LMV with different genetic bases. One dominant resistance gene, designated $L L M 1$, involved in blocking the replication or cell-to-cell movement of the LMV-0 isolate in the Columbia accession, was mapped to chromosome I and shown to be linked to the marker nga280. At the same time, genetic analyses of segregating $F 2$ populations were consistent with the restriction of the systemic movement of the LMV-AF199 isolate in Columbia being controlled by two dominant genes and with the complete resistance to all tested $L M V$ isolates of the Cape Verde islands ( $\mathrm{Cvi}$ ) accession being conferred by a single recessive resistance gene. Sequencing of the eukaryotic translation initiation factor $4 \mathrm{E}$ genes from the different LMV-resistant Arabidopsis accessions showed that these factors are not directly involved in the characterized resistance phenotypes.
\end{abstract}

The interaction between a plant and a virus may result in a number of biological situations, ranging from complete systemic invasion of the plant, usually accompanied by symptoms (full susceptibility), to the inability of the virus to mount a productive replication in the initially inoculated cells. A number of intermediate situations in which the virus is blocked more or less early in the plant invasion process also can be observed (Hull 2002). Knowledge of the plant and viral factors involved in the outcome of these interactions is crucial to further our understanding of the molecular determinism of key biological processes such as viral host range or plant resistance. Important advances have been made in recent years in the understanding of the molecular biology of the interactions between potyviruses and their hosts (Revers et al. 1999). The genus

Corresponding author: F. Revers, E-mail: revers@ bordeaux.inra.fr.
Potyvirus is the largest of the plant virus genera and its members cause severe losses to many crops (Shukla et al. 1994). Potyviruses are aphid transmitted and some of them are also seed borne. Their positive single-stranded RNA genome of approximately 10,000 nucleotides is polyadenylated at its $3^{\prime}$ end and covalently linked at its $5^{\prime}$ end to an approximately $25-\mathrm{kDa}$ virus-encoded protein (VPg). The genome encodes a polyprotein which is matured by three virus-encoded proteinases into approximately 10 mature viral proteins (Riechmann et al. 1992). In several host-potyvirus pathosystems, the VPg has been shown to be involved in overcoming host resistance genes or in the ability to infect specific host plants (Borgstrøm and Johansen 2001; Masuta et al. 1999; Rajamäki and Valkonen 1999, 2002; Revers et al. 1999). This protein also has been shown to interact with the eukaryotic translation initiation factor eIF4E or its isoform eIF(iso)4E (Léonard et al. 2000; Schaad et al. 2000; Wittmann et al. 1997), which recently were shown to play an important role in the potyviral cycle and to be involved in recessive resistances to potyviruses in several hosts (Duprat et al. 2002; Lellis et al. 2002; Ruffel et al. 2002; V. Nicaise and S. German-Retana, unpublished data). Together, these results suggest that, in different potyvirus-plant pathosystems, common viral and host factors repeatedly seem to be involved in determining the outcome of the interaction, underlying a conserved infection strategy in the genus Potyvirus, and support the hypothesis that plants carrying recessive resistance genes against viruses lack a function essential for a particular step of the viral cycle (Fraser 1992). This conserved strategy may, in turn, explain why recessive resistance genes represent approximately $40 \%$ of the known resistance genes to potyviruses (Provvidenti and Hampton 1992), whereas they represent only approximately 20\% for other virus groups (Fraser 1992). However, up to now, only the eIF4E genes have been identified to have a direct role in the plant-potyvirus interactions.

Among the numerous other resistance genes controlling potyvirus infection which have been characterized from a genetic standpoint, only two dominant resistant genes, RTM1 and RTM2, restricting long-distance Tobacco etch virus (TEV) movement, have been cloned in Arabidopsis thaliana and shown to encode a jacalin-like protein (Chisholm et al. 2000) and a small heat shock-like protein (Whitham et al. 2000), respectively. These resistant genes, specifically expressed in a sieve element (Chisholm et al. 2001), were shown to be specific for TEV because other potyviruses such as Potato virus $Y$ (PVY), Tobacco vein mottling virus (TVMV), and Turnip mosaic virus (TuMV) are able to infect Arabidopsis accessions bearing these two genes (Martín Martín et al. 1999; Whitham et al. 2000). Whether the products of these RTM genes act directly or indirectly to block the long-distance movement of TEV still remains to be elucidated. 
In order to identify new viral and host factors involved in potyvirus-host interactions, the high genetic variability of $A$. thaliana (Alonso-Blanco and Koornneef 2000) and the molecular and biological variability of Lettuce mosaic virus (LMV) isolates (Krause-Sakate et al. 2002; Revers et al. 1997a) have been exploited to identify Arabidopsis or LMV genetic determinants governing the interactions between these two partners. LMV is the causal agent of lettuce mosaic, one of the most devastating viral diseases in lettuce (Lactuca sativa) worldwide (Dinant and Lot 1992). Genetic resistance against LMV in lettuce is based on the use of either of two allelic recessive resistance genes, $\mathrm{mol}^{1}$ and $\mathrm{mol}^{2}$ (Dinant and Lot 1992), recently shown to correspond to allelic variants of the eIF4E gene (V. Nicaise and S. German-Retana, unpublished data). The recent emergence of LMV isolates, collectively named LMV-Most (Krause-Sakate et al. 2002), which combine resistance-breaking and seed-transmission properties, has raised the question of the durability of such recessive resistance genes in crops and created the need for the identification of other resistance sources against this virus.

In this study, screening of Arabidopsis accessions using three LMV isolates revealed the existence of a large variability in the outcome of LMV-Arabidopsis interactions. Viral and plant determinants of these interactions then were analyzed using reverse or forward genetic approaches.

\section{RESULTS}

\section{Variability in LMV-AF199 susceptibility identified among Arabidopsis accessions.}

In order to determine whether A. thaliana is a host for LMV, 35 accessions were inoculated manually with LMV-AF199, an isolate belonging to the LMV-Most group (Krause-Sakate et al. 2002). After 3 weeks, no visible symptoms were observed on plants, either on the inoculated leaves or on noninoculated parts such as other rosette leaves or inflorescence tissues. In order to evaluate the possibility of symptomless infections, inflorescence tissues of all inoculated plants were analyzed by enzyme-linked immunosorbent assay (ELISA) using a rabbit antiserum raised against purified LMV (Table 1). Twenty-eight accessions presented high ELISA values (at least 10-fold the value of the mock-inoculated controls) and the presence of LMV in the systemically infected inflorescence tissues was confirmed both by back inoculation to susceptible lettuce plants and by reverse transcriptase-polymerase chain reaction (RT-PCR) amplification of the coat protein region of the LMV genome from total RNA extracts (data not shown). In contrast, seven accessions presented ELISA values similar to those of the mock-inoculated controls even when the ELISA was repeated 4 to 6 weeks postinoculation (wpi). Back-inoculation from all the ELISA-negative accessions to susceptible lettuce plants confirmed the absence of systemic LMV accumulation in these plants.

In all accessions showing systemic LMV accumulation, infection by LMV-AF199 was detected at 25 days postinocula- tion (dpi) and even as early as 15 dpi in all plants of the accessions La-0, La-er, Ler, Ler-0, Pog-0, Mh-0, Shahdara, C24, Ws, Bay-0, Sh-0, Tsu-0, and RLD.

The possibility of seed transmission of LMV in Arabidopsis spp. also was examined. Approximately 200 15-day-old seedlings of the RLD, Ler, and Nd-1 accessions produced from seeds obtained from LMV-infected plants were analyzed by ELISA. All the ELISA were negative, demonstrating that LMV either is not seed borne in Arabidopsis spp. or is transmitted only at a very low rate, despite the fact that the virus was easily detected in seed pod tissues by ELISA (data not shown).

In order to further characterize the resistance phenotype of the seven accessions for which LMV was not detected in upper, noninoculated parts, ELISA were performed on inoculated leaves at 15 dpi (Table 1). Two accessions, Cvi-0 and Cvi-1, seemed to be unable to accumulate LMV in the inoculated leaves because the ELISA values obtained for these plants were similar to those from mock-inoculated leaves. Upon back-inoculation from the inoculated leaves of these two accessions to susceptible lettuce, no symptoms were observed. In contrast, five accessions, Col-0, Col-3, Col-5, Wt-1, and Ll-0, were ELISA positive in inoculated leaves. Therefore, these results suggest that two levels of resistance control LMV-AF199 infection in the Arabidopsis accessions tested. The first level of resistance, observed in the two Cvi accessions, seems to inhibit LMV multiplication or cell-to-cell movement and will be referred to as "local resistance", whereas the second level, observed in accessions Wt-1, Ll-0, Col-0, Col-3, and Col-5, corresponds to an inhibition of long-distance viral movement and will be referred to as "systemic resistance".

\section{Variability in susceptibility to other LMV isolates among Arabidopsis accessions.}

In order to test whether the two levels of resistance observed against LMV-AF199 also were active against other LMV isolates, selected Arabidopsis accessions were inoculated manually with LMV-0 and LMV-E, two well-characterized LMV isolates differing in their biological properties in lettuce (Revers et al. 1997a, 1997b), and with LMV-0-GUSclvHC and LMV-E-GUSHC, two GUS-tagged recombinant LMV isolates derived from LMV-0 and from LMV-E infectious cDNA clones, respectively (German-Retana et al. 2000; S. GermanRetana, unpublished data). Systemic LMV accumulation in inflorescence tissues was determined by ELISA 3 wpi and local LMV accumulation in the inoculated leaves was determined by GUS histochemical staining assays $10 \mathrm{dpi}$. A global analysis of these results showed that Arabidopsis accessions could be classified into seven classes, based on their behavior upon inoculation with the three LMV isolates used (Table 2). Both LMV-0 and LMV-E were able to infect a more restricted set of accessions than LMV-AF199, and all accessions showing resistance against LMV-AF199 also showed resistance to LMV-0 and to LMV-E, with the exception of Col accessions, in which a small percentage of plants repeatedly were observed to systemically accumulate LMV-E (Table 1). On the other hand, LMV-AF199

Table 1. Susceptibility of Arabidopsis thaliana to infection by Lettuce mosaic virus (LMV)-AF199a

\begin{tabular}{lcc}
\hline Accession or mutant & Local accumulation $^{\mathbf{b}^{2}}$ & Systemic accumulation $^{\mathbf{c}}$ \\
\hline La-0, La-er, Ler, Ler-0, Pog-0, Mh-0, Shahdara, WS, Bay-0, Sh-0, Gre-0, C24, Chi-0, RLD, & + \\
Tsu-0, Kas-1, Oy-0, Kin-0, Jl-1, St-0, In-0, Nd-0, Nd-1, Ge-1, Di-0, Vi-0, Zü-0, Aa-0 & + \\
Wt-1, L1-0, Col-0, Col-3, Col-5, Col-0 npr1-1, Col-0 pad4-1, Col-0 eds4-1, Col-0 ndr1-1, & + \\
Col-0 etr1-1, Col-0 jar1-1 & - \\
Cvi-0, Cvi-1 & - \\
\hline
\end{tabular}

$\mathrm{a}+=$ LMV accumulation and $-=$ no accumulation detected.

${ }^{\mathrm{b}}$ LMV accumulation in inoculated leaves as detected 10 days postinoculation by enzyme-linked immunosorbent assay (ELISA).

${ }^{\mathrm{c}}$ LMV accumulation in non inoculated inflorescence tissue as detected 3 weeks postinoculation by ELISA. 
appears to be able to overcome local or systemic resistance active against LMV-E or LMV-0 in a number of accessions. Among the accessions tested, only $\mathrm{Nd}-\mathrm{O}$ and $\mathrm{Nd}-1$ differed clearly in their susceptibility towards LMV-E and LMV-0, in that systemic infection by LMV-E was detected 3 wpi in both accessions, whereas LMV-0 systemic infection was never detected, even up to 6 wpi by ELISA, back-inoculation to susceptible lettuce, or RT-PCR. The patterns of GUS histochemical staining of leaves of these $\mathrm{Nd}$ accessions after inoculation with LMV-E-GUSHC and LMV-0-GUSclvHC (Fig. 1) gave similar results, indicating that resistance to $\mathrm{LMV}-0$ in $\mathrm{Nd}-0$ and $\mathrm{Nd}-1$ was not related to a decrease in replication or to slow cell-tocell movement of this isolate. In the LMV-0- and LMV-E-resistant accessions Di-0, Vi-0, Zü-0, Aa-0, Col-0, Col-3, Col-5, Cvi-0, and Cvi-1, no GUS activity was detected in inoculated leaves with either tagged virus, even upon stereomicroscope examination, which should have allowed the detection of single-cell infection foci resulting from a blockage of cell-to-cell movement (subliminal infection) (Fig. 1). Similarly, no hypersensitive-like lesions were observed at the macroscopic level (data not shown).

Analysis of the LMV-GUS inoculated leaves from susceptible accessions revealed other differences, mostly in the number and size of the infection foci. Indeed, some accessions such as Ler presented very few GUS spots or GUS spots of relatively small size, whereas in other accessions, such as Mh-0, GUS spots were consistently both more numerous and larger (Fig. 1). However, systemic infection was detected with a similar timing in all types of accessions (data not shown), suggesting that the number and size of infection foci in inoculated leaves does not directly control the kinetics of systemic infection.

\section{The LMV VPg is involved in systemic infection in the Nd accessions.}

To further analyze the molecular interactions between Arabidopsis spp. and LMV, Arabidopsis accessions belonging to some of the classes described above were studied. The LMV molecular determinant responsible for the difference between LMV-E and LMV-0 in the Nd-1 accession first was analyzed by a reverse genetic approach using recombinants constructed from infectious LMV-0 and LMV-E cDNA clones (Redondo et al. 2001; Yang et al. 1998). The pair of recombinants, 0xbaE and Exba0 (Redondo et al. 2001), first was used to show that the $3^{\prime}$ half of the LMV genome was involved in overcoming resistance to systemic invasion (Fig. 2). Because no LMV recombinants were available for this part of the genome, new recombinants were constructed (Fig. 2). Infectivity of these recombinant clones was assayed in susceptible lettuce and the recombinant regions were confirmed by RT-PCR and sequencing. Then, lettuce plants infected with the recombinants were used as source of inoculum to test the ability of these recombinants to systemically infect Nd-1 plants. For each recombinant, ELISA were performed 3 wpi using inflorescence tissues from three inoculated Nd-1 plants tested individually. Each experiment was repeated at least twice. ELISA-positive plants were analyzed by RT-PCR coupled with restriction fragment length polymorphism (RFLP) analysis of the amplification products to confirm the identity of the recombinants (data not shown). Only 0stafE, a LMV-0 clone carrying the LMV-E VPg, was able to overcome the Nd-1 resistance to LMV-0, whereas the symmetrical recombinant, Estaf0, and the other recombinants were not detected systemically in Nd-1.

Similarly, an LMV-0 recombinant in which the VPg coding region was replaced by that from LMV-AF199 also was able to overcome the blockage in systemic movement observed in accession Nd-1 (data not shown), demonstrating that, for both LMV-E and LMV-AF199, the resistance-breaking determinant is localized in the viral VPg.

Amino acid sequence alignment of the VPg of the three LMV isolates (GenBank accession numbers X97704 for LMV0, X97705 for LMV-E, and AJ278854 for LMV-AF199) showed only three positions $(2,121,2,169$, and 2,177$)$ at which the LMV-0 sequence simultaneously differed from those of both LMV-E and LMV-AF199 (Fig. 3).

\section{Local resistance to LMV-0 in the Columbia accession is controlled by $L L M 1$, a dominant resistance gene linked to the genetic marker nga280 on chromosome $I$.}

The Columbia accessions showed a local resistance against LMV-0 (Table 2). A number of resources for genetic mapping are available for this accession; therefore, the genetic analysis of this resistance was undertaken, using an F2 population and F9 recombinant inbred (RI) lines produced from a cross between Col-5 and Nd-1 (Holub and Beynon 1997) available from the Nottingham Arabidopsis Stock Center (NASC).

To characterize the genetic basis of the LMV-0 local resistance in Columbia, 96 plants of the $\mathrm{F} 2$ population were inoculated with LMV-0-GUSclvHC and the inoculated leaves were analyzed 10 dpi by a GUS histochemical assay. Similarly, 71 F2 plants were inoculated with LMV-0 and the inoculated leaves were tested by ELISA at 15 dpi. In both experiments, LMV-0 resistance segregated in a manner consistent with the

Table 2. Comparison of susceptibility of Arabidopsis accessions and mutants to infection by various Lettuce mosaic virus (LMV) isolates

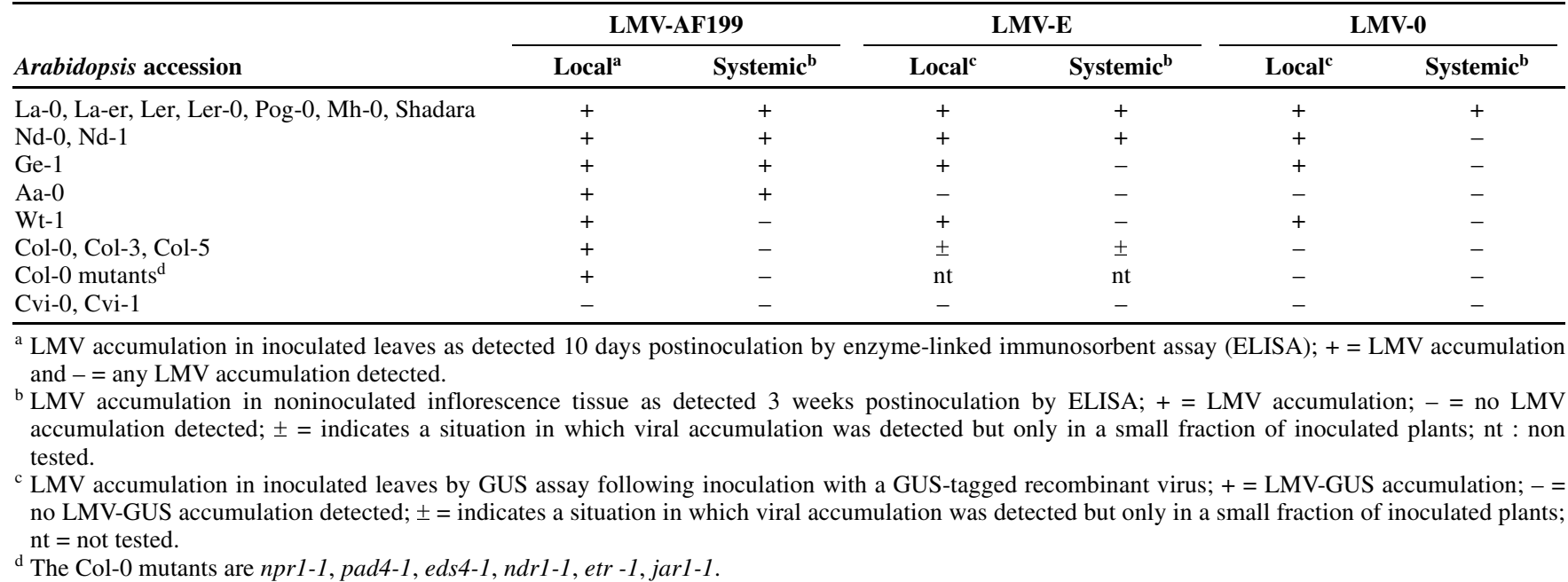


presence of a single dominant gene (71 resistant for 96 plants with LMV-0-GUSclvHC, $\chi^{2}=0.555$ for a 1:3 segregation; 56 resistant for 71 tested plants with LMV-0, $\chi^{2}=0.568$ ). This resistance locus was named $L L M I$ (local resistance to LMV).

In order to map $L L M 1$, plants from the RI population were inoculated with both LMV-0-GUSclvHC and LMV-0 and tested in the same way as the F2 population. Of the $89 \mathrm{RI}$ lines tested, 45 were resistant and 44 were susceptible. These data correspond to a ratio of the number of resistant versus susceptible lines of 1.02, which, again, is in agreement with a single gene model as suggested by the F2 population analysis. Using the molecular markers released on the NASC website and additional markers from J. Beynon (unpublished), a recombination analysis revealed that marker nga280 located on chromosome I was linked to $L L M 1$ with a recombination rate of $12.5 \%$ between these two loci (Table 3 ).

To analyze the mechanism of this LMV-0 resistance, Col-0 mutants with altered defense responses in systemic acquired resistance (SAR) or $R$ gene-mediated signaling defense pathways (Dangl and Jones 2001; Glazebrook 2001) were tested for their resistance to LMV-0 (Table 2). These included Col-0 plants with a mutation in the NPR1 gene (nprl-1), which are unable to activate SAR and present enhanced disease susceptibility (Glazebrook et al. 1996), and Col-0 plants with mutations in genes belonging to the two known signaling pathways downstream of nucleotide binding site-leucine rich repeat (NBS-LRR) resistance genes NDR1 (ndrl-1), PAD4 (pad4-1), and EDS1 (eds4-1) (Glazebrook et al. 1996). In addition, Col-0 jasmonate-resistant jarl-1 plants (Staswick et al. 1992) and Col-0 ethylene-insensitive etrl-1 plants (Bleecker et al. 1988) also were tested. Four plants of each mutant were inoculated with LMV-0 and LMV-0-GUSclvHC. GUS activity and ELISA were performed at 10 and 15 dpi for LMV-0-GUSclvHC- and LMV-0-inoculated leaves, respectively. Local resistance to LMV-0 was not compromised in any of these mutant plant lines; whereas, as a positive control in these experiments, the Ler plants inoculated in parallel all were infected successfully. These results support the hypothesis that the mechanism of local LMV-0 resistance in the Columbia accession differs from those controlled by the well-characterized defense pathways of Arabidopsis spp.

To further evaluate the stability of the local LMV-0 resistance in Columbia, Col-5 plants previously infected with $\mathrm{Cu}$ cumber mosaic virus (CMV) R strain, a virus belonging to the genus Cucumovirus and able to suppress posttranscriptional gene silencing (PTGS) (Lucy et al. 2000), were inoculated with LMV-0. As a control, CMV-infected plants of the Ler and Nd-1 accessions also were inoculated with LMV-0. At $15 \mathrm{dpi}$, no systemic LMV-0 infection was detected in the CMV-infected Col-5 plants, whereas LMV was detected in CMV-infected Ler and Nd-1 plants (data not shown). Thus, CMV infection did not suppress resistance to LMV in the Columbia accession. Identical results were obtained when plants were inoculated simultaneously with LMV and CMV on the same or on different leaves (data not shown). To determine whether the block in local LMV-0 accumulation results from the induction of a general antiviral response, LMV-infected Col-5 and Ler plants were inoculated with CMV 15 days after LMV inoculation, and CMV accumulation was evaluated by ELISA 10 days later. All plants were found to accumulate CMV, indicating that LMV resistance does not affect the susceptibility of the Columbia accession to CMV.

Given the LMV-0 infection phenotypes observed in the Col (local infection blockage) and $\mathrm{Nd}$ (systemic infection blockage) parents, the possibility existed that fully susceptible plants could be recovered in the F2 or RI lines populations. In all, 10 F2 plants and 10 RI lines, for which LMV-0 was detected by ELISA in inoculated leaves, were analyzed 3 wpi for systemic LMV-0 accumulation in inflorescence tissues. None of these plants were found to be systemically infected by LMV-0.

\section{Preliminary genetic analysis \\ of the LMV-AF199 systemic resistance}

in the Columbia accession and of the LMV local resistance in the Cvi accession.

The Columbia accession showed a systemic resistance to LMV-AF199, whereas the Cvi accession showed a local resistance to this isolate as well as to the other LMV isolates tested. As a preliminary genetic analysis, two F2 populations produced from these accessions were analyzed. From the F2 population (Col-5 $\times$ Nd-1) described above, 308 plants were inoculated with LMV-AF199 and inflorescence tissue was analyzed by ELISA 3 wpi. Of these, 23 plants $(7.5 \%)$ showed systemic accumulation of LMV-AF199, whereas the remaining 285 plants $(92.5 \%)$ were found resistant. These data are consistent with a segregation ratio expected for two nonlinked dominant loci independently conferring resistance $\left(\chi^{2}=0.76\right.$ for a $15: 1$ segregation). In addition, this systemic resistance was evaluated in the Col- 0 mutant lines described above but was not affected in any of these lines (Table 1).

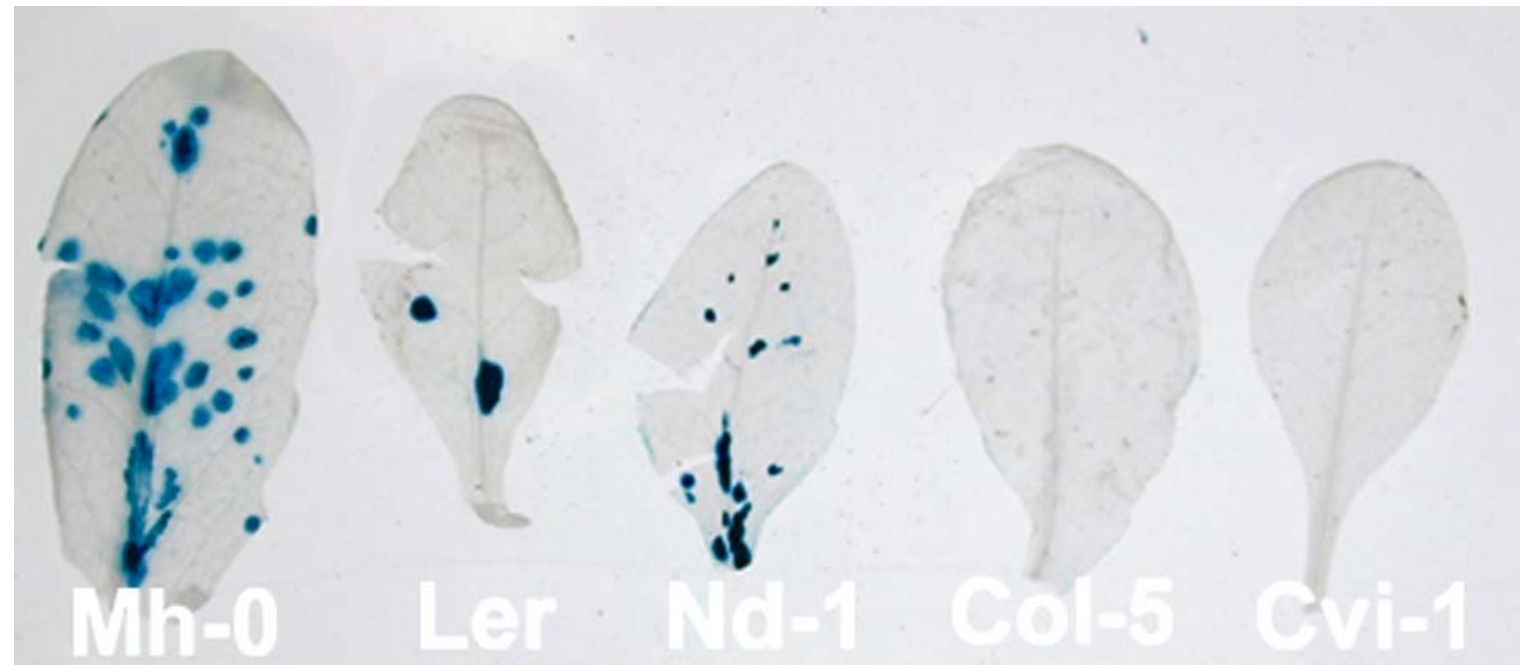

Fig. 1. Lettuce mosaic virus-0-GUSclvHC multiplication in inoculated leaves of Arabidopsis accessions. GUS assays were performed 8 days postinoculation. Accession names are indicated under each leaf. 
Plants of an F2 population produced by a cross between Cvi-1 and Ler, an LMV-susceptible accession, were inoculated with LMV-AF199 and analyzed by ELISA at 3 wpi. Of 194 plants tested, 131 were susceptible $(67.5 \%)$, suggesting that, in Cvi, the local resistance is controlled by a single recessive locus $(\chi 2=$ 5.78 for a 3:1 ratio). Mixed infections with CMV produced and analyzed as described above showed that the systemic resistance in Columbia and the local resistance in Cvi are not suppressed by a heterologous virus able to suppress PTGS, and that LMV-AF199 inoculations in Columbia and Cvi do not trigger a general antiviral defense effective against CMV (results not shown).

Eukaryotic translation initiation factors eIF4E and eIF(iso)4E of Arabidopsis spp. are not directly involved in the resistance mechanisms against LMV identified in the $\mathrm{Nd}$, Col, and $\mathrm{Cvi}$ accessions.

Several recent studies have shown that the eukaryotic translation initiation factors eIF4E and eIF(iso) $4 \mathrm{E}$ interact with the VPg of potyviruses (Léonard et al. 2000; Schaad et al. 2000; Wittmann et al. 1997) and have implicated these genes in recessive resistance mechanisms active against potyviruses in Arabidopsis spp., pepper, and lettuce (Duprat et al. 2002; Lellis

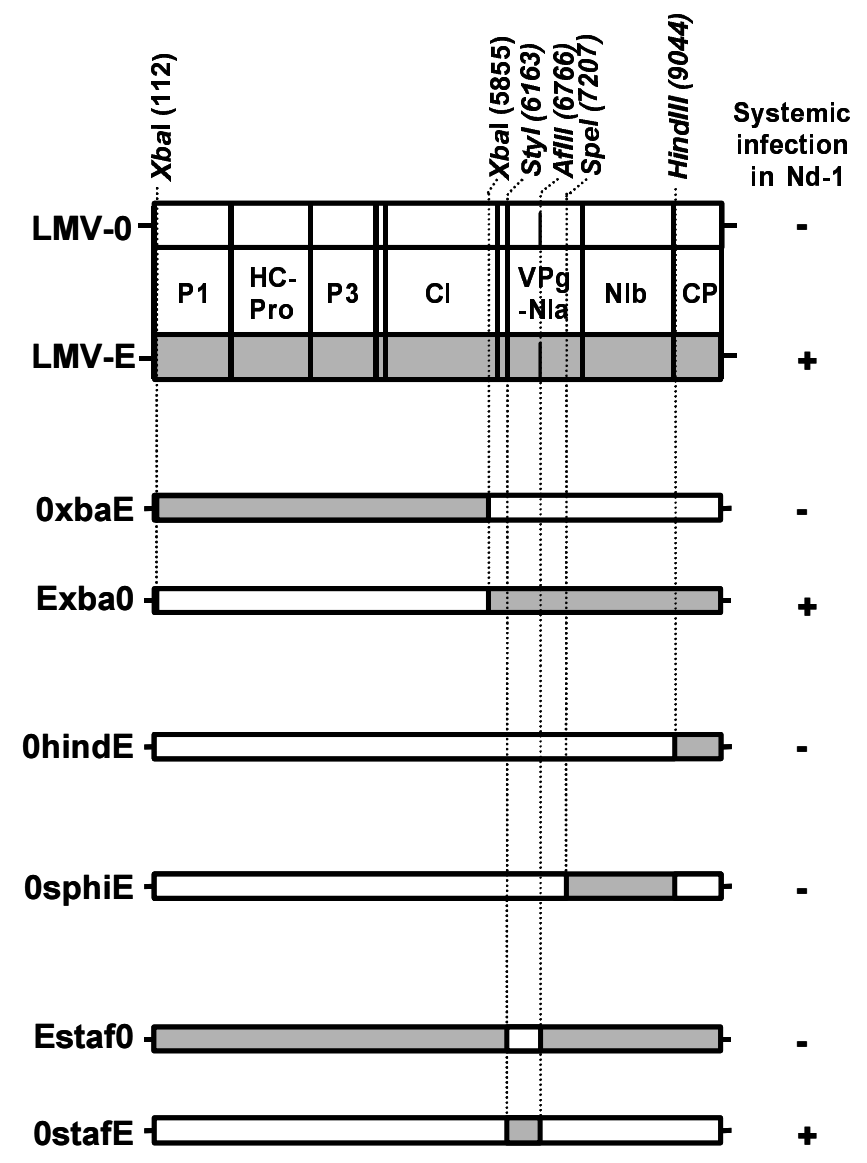

Fig. 2. Schematic representation of the genome of Lettuce mosaic virus (LMV) and of the LMV recombinants constructed between LMV-0 and LMV-E. Coding regions are indicated in white and gray boxes for LMV0 and LMV-E, respectively. The positions of cleavage sites between the viral proteins are indicated by vertical lines. The name of each protein is indicated between the two LMV genomes. Restriction sites used to construct the recombinants are indicated at the top, with their position along the LMV genome. The ability of each recombinant to infect systemically accession $\mathrm{Nd}-1$ is indicated on the right; + indicates a positive systemic infection and - indicates no systemic infection detected. et al. 2002; Ruffel et al. 2002; V. Nicaise and S. GermanRetana, unpublished data). In order to investigate the possibility that the $e I F 4 E$ genes are involved in the LMV resistance in $\mathrm{Nd}-1$, in which the VPg is a resistance-breaking determinant or in the LMV recessive resistance in Cvi-1, the $\mathrm{Nd}-1$ and $\mathrm{Cvi}-1$ $e I F 4 E$ and $e I F$ (iso) $4 E$ gene sequences were determined and aligned with those of other Arabidopsis accessions (GenBank accessions NM_117914 [Columbia eIF4E], AY086496 [WS/Ler eIF4E], Y10548 [Ler eIF4E], NM_122953 [Columbia eIF(iso)4E], AY056630 [WS/Ler eIF(iso)4E], and Y10547 [Ler eIF(iso)4E]). Alignment of all these sequences showed $100 \%$ nucleotide sequence identity for each one of these genes. This absence of allelic variation suggests that the eIF4E and eIF(iso) $4 E$ genes from the $\mathrm{Nd}-1$, Cvi-1, and Col- 0 accessions are not the basis for the various forms of LMV resistance identified in this study.

\section{DISCUSSION}

In this study, the high natural genetic variability of $A$. thaliana was exploited to establish an LMV-Arabidopsis pathosystem. Indeed, the screening of Arabidopsis accessions with three well-characterized LMV isolates, LMV-AF199, LMV-E, and LMV-0, revealed variability in the susceptibility to these isolates of the accessions tested. Approximately $80 \%$ of the accessions tested with LMV-AF199 were found to be fully susceptible; however, in all cases, the resulting systemic infections were found to be symptomless and to develop more slowly than infection in susceptible lettuce cultivars. Symptomless and slower-infection phenotypes also were observed in Arabidopsis spp. with TEV, another member of genus Potyvirus (Mahajan et al. 1998). In order to explain these differences in symptom expression and infection timing, several hypotheses can be proposed. Because viruses need a panel of host factors for the different steps of their cycle in plants, one hypothesis is that the affinity between hosts and viral factors provides a basis for genetic variation in the timing and extent of viral infection. A second hypothesis is that one or some active defense responses are overcome less efficiently by the virus in different plant species, resulting in a delayed systemic infection. With regard to this second hypothesis, RNA silencing has been shown to be an antiviral defense system in higher plants against which various viruses, including potyviruses, have developed viral-encoded suppressors (Voinnet 2001). In the case of symptomless LMV and TEV infections in Arabidopsis spp., suppression of RNA silencing may be less efficient, resulting in the delayed and symptomless infection phenotype. This hypothesis, however, is weakened by the mixed LMV-CMV infections reported here, in which no beneficial effect of the presence of CMV could be noticed despite the known ability of CMV to suppress the RNA silencing defense pathway (Lucy et al. 2000).

Among the resistant accessions, at least two different resistance phenotypes were identified. The first phenotype (local resistance) was characterized by an absence of detectable viral accumulation in inoculated leaves and the second (systemic resistance) by a failure of LMV to accumulate in noninoculated tissues, likely to result from a blockage in long-distance viral movement.

By a reverse genetic approach, the LMV VPg was identified as the viral determinant involved in overcoming the blockage in long-distance movement of LMV-0 in accession $\mathrm{Nd}-1$. Among the three amino acid positions which differ between LMV-0 and the two others LMV isolates, LMV-E and LMVAF199, position 2,121 (Serine in LMV-0, Glycine in LMV-E and LMV-AF199) is located in the central region of $\mathrm{VPg}$, in which several mutations associated with the ability to over- 
come recessive resistances have been identified for several potyviruses, such as TEV (Schaad et al. 1997), TVMV (Nicolas et al. 1997), Pea seed-borne mosaic virus (Keller et al. 1998), PVY (Masuta et al. 1999), and Potato virus A (PVA) (Rajamäki and Valkonen 1999, 2002). As in the observations reported here, no effect on the cell-to-cell movement efficiency accompanied the systemic blockage of TEV in tobacco (Schaad et al. 1997) or of PVA in Nicandra physaloides (Rajamäki and Valkonen 1999) and in Solanum commersonii (Rajamäki and Valkonen 2002). However, the precise function of the VPg in these resistance mechanisms remains to be determined, as well as the identity of the host factor or factors involved. In the case of $N$. tabacum, segregation analysis in an F2 population indicated involvement of two nonlinked recessive genes in the TEV resistance which have not yet been cloned (Schaad and Carrington 1996). In the Nd-1 accession, the genetic basis for LMV-0 resistance has not yet been established, although the absence of systemic accumulation of LMV-0 in Col-5 $\times$ Nd-1 F2 and RI line plants suggests that this resistance could be a complex trait controlled by at least two genes. Sequence determination of the eIF4E and eIF(iso) $4 E$ genes and comparison with other Arabidopsis accessions suggested that these host genes are not involved in this resistance to LMV-0.

With the aim to identify the genetic bases and the resistance genes which control LMV infection in the various Arabidopsis accessions, genetic analyses of the local and systemic resistance phenotypes observed were performed. For the local resistance phenotype observed in Columbia with LMV-0, the genetic analysis revealed the involvement of one locus designated $L L M 1$. The LMV-0 resistance locus $L L M 1$, identified in Col-5, was mapped to chromosome I using Col-5 $\times$ Nd-1 RI lines, and was found to be linked to marker nga280. In the region between markers GAPB and genea, which flank nga280, several putative disease resistance genes were identified. Because of the dominant nature of LLM1 and of the local resistance phenotype it confers, it is tempting to speculate that LLM1 corresponds to one of the NBS-LRR genes (Dangl and Jones 2001) belonging to the $R$ gene cluster identified in this region of chromosome I. This hypothesis is strengthened by two observations: i) that this cluster contains $R P P 7$ as well as homologues of RRP8 (locus AT1G53350) and RPP13 (locus AT1g59218), three resistance genes whose function is known to be independent of the well-known Arabidopsis resistance pathways controlled by PAD4, NDR1, and EDS1 (Glazebrook 2001); and ii) that the function of $L L M 1$ was shown here to be independent of these genes as well as of a number of other genes $(N P R l)$ or mediators (salycilate, ethylene, and jasmonate) involved in Arabidopsis resistance mechanisms. However, unambiguous identification of $L L M 1$ as a classical $R$ gene acting through the $R P P 7$ signaling pathway clearly will require its identification through positional cloning or through a candidate gene approach.

Concerning the local resistance to all LMV isolates tested in $\mathrm{Cvi}$, the $\mathrm{F} 2$ population analysis suggests that a single recessive locus is involved in the resistance phenotype. In addition, sequence comparisons of both eIF4E genes in several Arabidopsis accessions, including $\mathrm{Cvi}$, revealed a complete identity between all alleles, therefore excluding the role of these initiation factors in the resistance to LMV in Cvi. These results suggest that the susceptibility allele at this locus is either another host factor required for the successful completion for the potyvirus cycle or a negative regulator of resistance. Alternatively, it cannot be ruled out at this point that transcriptional, translational, or posttranslational defects of one or the other of the eIF4E isoforms could be involved in LMV resistance. Analysis of RI lines produced from a cross between the LMV-suscepti- ble accessions Ler and Cvi (Alonso-Blanco et al. 1998) should confirm the involvement of such a recessive resistance gene and facilitate its mapping and cloning.

The genetic basis of the systemic resistance to LMV-AF199 in Columbia seems more complex because a two-gene model is proposed. This resistance does not involve a macroscopically visible hypersensitive response or a known resistance pathway, and is not affected by CMV infection, an unrelated virus which is able to suppress RNA silencing (Lucy et al. 2000). This resistance system appears to be similar to the one which inhibits long-distance movement of TEV in Col-3 (Mahajan et al. 1998, Whitham et al. 2000). In this accession, at least two dominant genes, RTM1, which encodes a jacalin-like protein (Chisholm et al. 2000), and RTM2, which encodes a small, heat shock-like protein (Whitham et al. 2000), are involved in TEV resistance. RTM1 was mapped near the top of chromosome I (Mahajan et al. 1998) and RTM2 near the top of chromosome V (Whitham et al. 1999). A more detailed genetic analysis of the systemic resistance to LMV-AF199 in Columbia should clarify whether the RTM loci are involved in this resistance.

To conclude, the data reported here support the idea that screening of Arabidopsis accessions with different potyviruses can reveal different sets of genes for which co-evolution between each virus and Arabidopsis accessions has led to the establishment of a virus-specific infection phenotype. Indeed, LMV interactions with Arabidopsis accessions are different from those of two other well-studied potyviruses, TEV (Mahajan et al. 1998) and TuMV (Martín Martín et al. 1999), in this plant species. Thus, genetic and molecular analysis of such pathosystems, coupled with the wealth of genetic and genomic resources now available for this plant, provide a very powerful means to identify viral and host factors governing potyvirushost interactions.

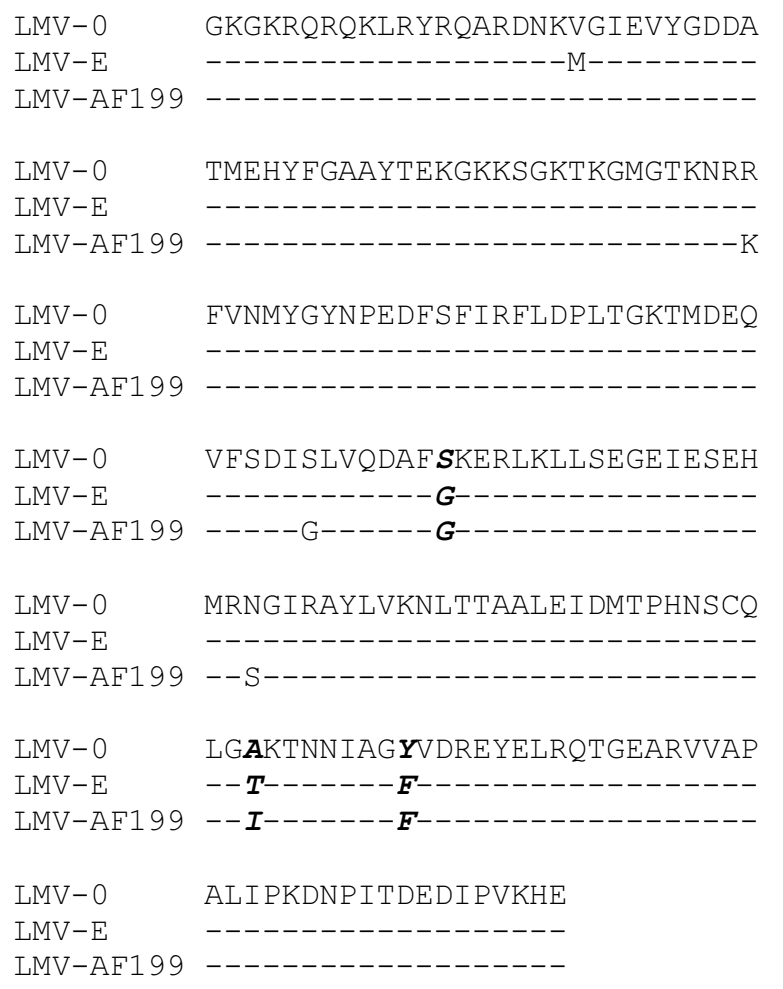

Fig. 3. Amino acid sequence alignment of the genome-linked protein of isolates Lettuce mosaic virus (LMV)-0, LMV-E, and LMV-AF199. Bold and italicized amino acids are positions at which the sequences of both LMV-E and LMV-AF199 differ from that of LMV-0. Hyphens indicate identical amino acids. 


\section{MATERIALS AND METHODS}

\section{Plant materials, virus, and inoculation.}

Seed of all Arabidopsis accessions, RI lines, and mutants were obtained from NASC, except Bay-0 and Shahdara (gift of O. Loudet, INRA, Versailles, France), RLD (gift of C. Robaglia, CEA, Cadarache, France), the ndrl-1 mutant (gift of B. Staskawicz, University of California, Davis, U.S.A.), the F2 Col- $5 \times$ Nd-1 seed (gift of Y. Marco, INRA, Toulouse, France), and the F1 Cvi $\times$ Ler seed (gift of M. Koornneef, Wageningen University, The Netherlands). The lettuce cv. Trocadéro, turnip (Brassica rapa), and Nicotiana tabacum $\mathrm{cv}$. Xanthi were used to propagate LMV isolates, TuMV, and CMV, respectively. All plants were grown under greenhouse conditions (16-h day length, 18 to $25^{\circ} \mathrm{C}$ ) and maintained in insect-proof cages after inoculation. Mechanical inoculation of 4- to 5-week-old Arabidopsis plants was performed as previously described (Revers et al. 1997a). Plants were reinoculated on different leaves 3 to 5 days later to ensure infection. The LMV isolates LMV-0, LMV-E, and LMVAF199 used in this study have been described by Revers and associates (1997a and b) and Krause-Sakate and associates (2002).

\section{ELISA, RT-PCR, and GUS assay.}

ELISA was performed as described by Revers and associates (1997a). An ELISA result was considered as positive when its value was at least three times the healthy controls value. RTPCR was performed using the primers NIb and P4 as described by Revers and associates (1999), from semipurified total RNA preparations (Bertheau et al. 1998).

Histochemical GUS staining was performed as described by German and associates (2000).

\section{Construction of LMV recombinants.}

Construction of the two recombinants $0 x b a E$ and Exba0 has been described by Redondo and associates (2001). For the recombinants OhindE, 0sphiE, Estaf0, and 0stafE, restriction sites (Fig. 2) were used to exchange the different regions between full-length infectious clones of LMV-0 and LMV-E. Particle bombardment was used to infect lettuce seedlings with these full-length cDNA constructs, as described by Redondo and associates (2001). Infected lettuce plants were further used as the source of inoculum for the inoculation of Arabidopsis plants. Identity of each recombinant was checked by RT-PCR (Revers et al. 1997a), using semipurified total RNA preparations as described above and primers chosen to flank the junction regions of the exchanged fragments. The identity of the recombinants finally was determined by RFLP analysis or sequencing of these amplified fragments.

\section{Cloning of the eIF4E and eIF(iso) $4 \mathrm{E}$ cDNA from the Cvi and Nd-1 accessions.}

Total RNAs were extracted from 100 to $200 \mathrm{mg}$ of rosette leaf tissues using TRI Reagent (Sigma-Aldrich, St Louis). Total cDNAs were synthesized from $5 \mu \mathrm{g}$ of total RNAs using 15 units of AMV Reverse Transcriptase (Amersham Biosciences, Uppsala, Sweden) and $1 \mu \mathrm{M}$ oligo-dT in $50 \mu \mathrm{l}$, incubated for $1 \mathrm{~h}$

Table 3. Percent recombination between molecular markers and Lettuce mosaic virus (LMV) resistance genes in Col-5 x Nd-1 recombinant inbred lines

\begin{tabular}{|c|c|c|c|c|c|}
\hline $\begin{array}{l}\text { Chromosome, } \\
\text { marker }\end{array}$ & Position $(\mathbf{c M})^{\mathrm{a}}$ & Col-5/Nd-1 ${ }^{b}$ & Ratio $^{c}$ & $\begin{array}{l}\text { Recombinant lines/total lines } \\
\text { for } L L M 1^{\mathrm{d}}\end{array}$ & Recombination (\%) for $L L M 1^{\mathrm{e}}$ \\
\hline \multicolumn{6}{|l|}{ I } \\
\hline nga59 & 2.90 & $42 / 50$ & 0.84 & $36 / 85$ & 36.7 \\
\hline nga63 & 11.48 & $41 / 52$ & 0.79 & $39 / 86$ & 41.5 \\
\hline SO392 & 46.71 & $51 / 42$ & 1.21 & $36 / 86$ & 36.0 \\
\hline gapB & 61.21 & $49 / 32$ & 1.53 & $23 / 75$ & 22.1 \\
\hline nga280 & 83.83 & $36 / 50$ & 0.72 & $16 / 80$ & 12.5 \\
\hline genea & 88.90 & $30 / 57$ & 0.53 & $24 / 81$ & 21.12 \\
\hline adh & 117.52 & $25 / 66$ & 0.38 & $40 / 84$ & 45.5 \\
\hline \multicolumn{6}{|l|}{ II } \\
\hline $\mathrm{m} 246$ & 11.03 & $30 / 48$ & 0.63 & $40 / 72$ & 62.5 \\
\hline PhyB & 34.45 & $37 / 54$ & 0.69 & $40 / 85$ & 44.4 \\
\hline gpa1 & 48.9 & $32 / 32$ & 1.00 & $35 / 58$ & 76.1 \\
\hline nga361 & 63.02 & $39 / 55$ & 0.71 & $38 / 87$ & 38.8 \\
\hline T9J23 & 92.0 & $42 / 49$ & 0.86 & $35 / 84$ & 35.7 \\
\hline \multicolumn{6}{|l|}{ III } \\
\hline nga126 & 16.35 & $22 / 72$ & 0.31 & $45 / 87$ & 53.6 \\
\hline nga162 & 20.56 & $39 / 55$ & 0.71 & $43 / 87$ & 48.9 \\
\hline MMJ24 & 48.45 & $51 / 42$ & 1.21 & $49 / 87$ & 64.5 \\
\hline nga707 & 78.25 & $53 / 38$ & 1.39 & $45 / 84$ & 57.7 \\
\hline nga112 & 87.88 & $37 / 28$ & 1.32 & $33 / 60$ & 61.1 \\
\hline \multicolumn{6}{|l|}{ IV } \\
\hline T18A10 & 1.0 & $56 / 35$ & 1.60 & $47 / 84$ & 63.5 \\
\hline nga8 & 26.56 & $59 / 34$ & 1.73 & $45 / 86$ & 54.9 \\
\hline g3883 & 64.15 & $41 / 34$ & 1.20 & $33 / 69$ & 45.8 \\
\hline nga1107 & 104.73 & $43 / 50$ & 0.86 & $37 / 86$ & 37.8 \\
\hline \multicolumn{6}{|l|}{ V } \\
\hline nga225 & 14.31 & $42 / 33$ & 1.27 & $36 / 71$ & 51.4 \\
\hline CA72 & 29.6 & $49 / 42$ & 1.17 & $44 / 85$ & 53.7 \\
\hline nga139 & 50.48 & $43 / 45$ & 0.96 & $42 / 82$ & 52.5 \\
\hline nga76 & 68.4 & $43 / 39$ & 1.10 & $41 / 77$ & 56.9 \\
\hline mi61 & 98.19 & $31 / 49$ & 0.63 & $45 / 75$ & 75.0 \\
\hline MUD21 & 131.20 & $60 / 31$ & 1.94 & $37 / 84$ & 39.4 \\
\hline
\end{tabular}

a Position obtained from the Nottingham Arabidopsis Stock Centre website.

${ }^{\mathrm{b}}$ Each fraction represents, for a given marker, the number of lines showing the Col-5 phenotype versus the number of lines showing the Nd-1 phenotype.

${ }^{\mathrm{c}}$ Calculated ratios of the fractions from the previous column.

${ }^{\mathrm{d}}$ Number of lines for which a recombination event was detected between a given marker and the LMV-0 resistance gene LLM1.

${ }^{\mathrm{e}}$ Percent recombination calculated using the equation $r=R / 2(1-R)$ (Haldane and Waddington 1931), where $R$ is the calculated ratio from the previous column. 
at $42^{\circ} \mathrm{C}$. PCR amplification was performed using $5 \mu \mathrm{l}$ of total cDNAs in $50-\mu \mathrm{l}$ reactions containing 0.5 units of Extra-Pol I Taq ADN polymerase (Eurobio, Les Ulis, France), using $1 \mu \mathrm{M}$ of oligonucleotide primers. The primers 5'AGAAAGAGAAGCAGTTCGGAGAAACAATG (the nucleotides underlined show the first codon of the coding region) and 5'AATGCAAAGATTTGAGAGGTTTCA (the nucleotides underlined show the stop codon) were used to amplify the complete coding region of eIF4E, and the primers 5'CAGAAGAAAACTCAACTGCGAAGAATATG and 5'TCTGGCTTCACACTCGTTTCTTCA were used to amplify the complete coding region of eIF(iso)4E. The cycling conditions were $20 \mathrm{~s}$ of denaturation at $92^{\circ} \mathrm{C}, 30 \mathrm{~s}$ of annealing at $54^{\circ} \mathrm{C}$, and $1 \mathrm{~min}$ of elongation at $72^{\circ} \mathrm{C}$ after an initial denaturation at $95^{\circ} \mathrm{C}$ for 2 min using an iCycler thermal cycler (Bio-Rad Laboratories, Hercules, CA, U.S.A.). The pGEM-T Easy vector system (Promega Corp., Madison, WI, U.S.A.) was used to clone PCR products. Automated DNA sequencing of at least three clones of each construct or of noncloned PCR products was performed at Qbiogene (Evry, France).

The nucleotide sequences were compared with other $A$. thaliana eIF4E and eIF(iso) $4 E$ retrieved in GenBank using the program Blast (Altschul et al. 1990) and aligned using ClustalW (Thompson et al. 1994), which generates and uses a distance dendrogram (Saitou and Nei 1987) to construct multiple sequence alignments.

\section{ACKNOWLEDGMENTS}

We thank J. Beynon (H.R.I., Wellesbourne, U.K.) for the unpublished data about the Col-5 $\times$ Nd-1 RI lines, Y. Marco (CNRS-INRA, Toulouse, France) for the F1 Col-5 $\times$ Nd-1 seed, M. Koornneef (Wageningen University, The Netherlands) for the F2 Cvi $\times$ Ler seed, O. Loudet (INRA, Versailles, France) for the Bay-0 and Shahdara accessions, C. Robaglia (CEA, Cadarache, France) for the RLD accession, B. Staskawicz (University of California, Berkeley, U.S.A.) for the ndrl-1 mutant, C. Béclin (INRA, Versailles, France) for the CMV-R strain, Hervé Lot (INRA, Avignon, France) for the early Arabidopsis experiments prior to this work, S. Poulain for his assistance in the cloning experiments, S. German-Retana for the unpublished data and for comments on the manuscript, V. Schurdi-Levraud for critically reading the manuscript, and $\mathrm{K}$. Mayo-Candresse for improving the English of the manuscript.

\section{LITERATURE CITED}

Alonso-Blanco, C., and Koornneef, M. 2000. Naturally occurring variation in Arabidopsis: An underexploited resource for plant genetics. Trends Plant Sci. 5:22-29.

Alonso-Blanco, C., Peeters, A. J., Koornneef, M., Lister, C., Dean, C., van den Bosch, N., Pot, J. and Kuiper, M. T. 1998. Development of an AFLP based linkage map of Ler, Col and Cvi Arabidopsis thaliana ecotypes and construction of a Ler/Cvi recombinant inbred line population. Plant J. 14:259-271.

Altschul, S. F., Gish, W., Miller, W., Myers, E. W., and Lipman, D. J. 1990. Basic local alignment search tool. J. Mol. Biol. 215:403-410.

Bertheau, Y., Frechon, D., Toth, I. K., and Hyman, L. J. 1998. DNA amplification by polymerase chain reaction (PCR). Pages 39-59 in: Methods for the detection and quantification of Erwinia carotovora subsp. atroseptica on potatoes. M. C. M. Perombelon and J. M. van der Wolff, eds. Scottish Crop Research Institute, Invergowrie, Dundee, Scotland.

Bleecker, A. B., Estelle, M. A., and Somerville, C. 1988. Insensitivity to ethylene conferred by a dominant mutation in Arabidopsis thaliana. Science 241:1086-1089.

Borgstrøm, B., and Johansen, I. E. 2001. Mutations in pea seedborne mosaic virus genome-linked protein VPg after pathotype-specific virulence in Pisum sativum. Mol. Plant-Microbe Interact. 14:707-714.

Chisholm, S. T., Mahajan, S. K., Whitham, S. A., Yamamoto, M. L., and Carrington, J. C. 2000. Cloning of the Arabidopsis RTM1 gene, which controls restriction of long-distance movement of tobacco etch virus. Proc. Natl. Acad. Sci. U.S.A. 97:489-494.

Chisholm, S. T., Parra, M. A., Anderberg, R. J., and Carrington, J. C. 2001. Arabidopsis RTM1 and RTM2 genes function in phloem to re- strict long-distance movement of tobacco etch virus. Plant Physiol. 127:1667-1675.

Dangl, J. L., and Jones, J. D. 2001. Plant pathogens and integrated defence responses to infection. Nature 411:826-833.

Dinant, S., and Lot, H. 1992. Lettuce mosaic virus. Plant Pathol. 41:528542.

Duprat, A., Caranta, C., Revers, F., Menand, B., Browning, K., and Robaglia, C. 2002. The Arabidopsis eucaryotic initiation factor (iso) $4 \mathrm{E}$ is dispensable for plant growth but required for susceptibility to potyviruses. Plant J. 32:927-934.

Fraser, R. S. S. 1992. The genetics of plant-virus interactions: Implications for plant breeding. Euphytica 63:175-185.

German-Retana, S., Candresse, T., Alias, E., Delbos, R.-P., and Le Gall, O. 2000. Effects of green fluorescent protein or b-glucuronidase tagging on the accumulation and pathogenicity of a resistance-breaking lettuce mosaic virus isolate in susceptible and resistant lettuce cultivars. Mol. Plant-Microbe Interact. 13:316-324.

Glazebrook, J. 2001. Genes controlling expression of defense responses in Arabidopsis-2001 status. Curr. Opin. Plant Biol. 4:301-308.

Glazebrook, J., Rogers, E. E., and Ausubel, F. M. 1996. Isolation of Arabidopsis mutants with enhanced disease susceptibility by direct screening. Genetics 143:973-982.

Haldane, J. B. S., and Waddington, C. H. 1931. Inbreeding and linkage. Genetics 16:357-374.

Holub, E., and Beynon, J. 1997. Symbiology of mouse-ear cress (Arabidopsis thaliana) and oomycetes. Adv. Bot. Res. 24:227-273.

Hull, R. 2002. Matthews' Plant Virology, fourth ed. Academic Press, London.

Keller, K. E., Johansen, I. E., Martin, R. R., and Hampton, R. O. 1998. Potyvirus genome-linked protein (VPg) determines pea seed-borne mosaic virus pathotype-specific virulence in Pisum sativum. Mol. Plant-Microbe Interact. 11:124-130.

Krause-Sakate, R., Le Gall, O., Fakhfakh, H., Peypelut, M., Marrakchi, M., Varveri, C., Pavan, M. A., Souche, S., Lot, H., Zerbini, F. M., and Candresse, T. 2002. Molecular characterization of Lettuce mosaic virus field isolates reveals a distinct and widespread type of resistancebreaking isolate: LMV-Most. Phytopathology 92:563-572.

Lellis, A. D., Kasschau, K. D., Whitham, S. A., and Carrington, J. C. 2002. Loss-of-susceptibility mutants of Arabidopsis thaliana reveal an essential role for eIF(iso)4E during potyvirus infection. Curr. Biol. 12:1046-1051.

Léonard, S., Plante, D., Wittmann, S., Daigneault, N., Fortin, M. G., and Laliberté, J. F. 2000. Complex formation between potyvirus VPg and translation eukaryotic initiation factor $4 \mathrm{E}$ correlates with virus infectivity. J. Virol. 74:7730-7773.

Lucy, A. P., Guo, H. S., Li, W. X., and Ding, S. W. 2000. Suppression of post-transcriptional gene silencing by a plant viral protein localized in the nucleus. EMBO (Eur. Mol. Biol. Organ.) J. 19:1672-1680.

Mahajan, S. K., Chisholm, S. T., Whitham, S. A., and Carrington, J. C. 1998. Identification and characterization of a locus (RTM1) that restricts long-distance movement of tobacco etch virus in Arabidopsis thaliana. Plant J. 14:177-186.

Martín Martín, A., Cabrera y Poch, H. L., Martinez Herrera, D., and Ponz, F. 1999. Resistances to turnip mosaic potyvirus in Arabidopsis thaliana. Mol. Plant-Microbe Interact. 12:1016-1021.

Masuta, C., Nishimura, M., Morishita, H., and Hataya, T. 1999. A single amino acid change in viral genome-associated protein of Potato virus $y$ correlates with resistance breaking in "Virgin A mutant" tobacco. Phytopathology 89:118-123.

Nicolas, O., Dunnington, S. W., Gotow, L. F., Pirone, T. P., and Hellmann, G. M. 1997. Variations in the VPg protein allow a potyvirus to overcome $v a$ gene resistance in tobacco. Virology 237:452-459.

Provvidenti, R., and Hampton, R. O. 1992. Sources of resistance to viruses in the Potyviridae. Arch. Virol. (Suppl. 5):189-211.

Rajamäki, M. L., and Valkonen, J. P. 1999. The 6K2 protein and the VPg of potato virus A are determinants of systemic infection in Nicandra physaloides. Mol. Plant-Microbe Interact. 12:1074-1081.

Rajamäki, M. L., and Valkonen, J. P. 2002. Viral genome-linked protein (VPg) controls accumulation and phloem-loading of a potyvirus in inoculated potato leaves. Mol. Plant-Microbe Interact. 15:138-149.

Redondo, E., Krause-Sakate, R., Yang, S. J., Lot, H., Le Gall, O., and Candresse, T. 2001. Lettuce mosaic virus pathogenicity determinants in susceptible and tolerant lettuce cultivars map to different regions of the viral genome. Mol. Plant-Microbe Interact. 14:804-810.

Revers, F., Le Gall, O., Candresse, T., and Maule, A. J. 1999. New advances in understanding the molecular biology of plant/potyvirus interactions. Mol. Plant-Microbe Interact. 12:367-376.

Revers, F., Lot, H., Souche, S., Le Gall, O., Candresse, T., and Dunez, J. 1997a. Biological and molecular variability of lettuce mosaic virus isolates. Phytopathology 87:397-403. 
Revers, F., Yang, S. J., Walter, J., Souche, S., Lot, H., Le Gall, O., Candresse, T., and Dunez, J. 1997b. Comparison of the complete nucleotide sequences of two isolates of lettuce mosaic virus differing in their biological properties. Virus Res. 47:167-177.

Riechmann, J. L., Lain, S., and Garcia, J. A. 1992. Highlights and prospects of potyvirus molecular biology. J. Gen. Virol. 73:1-16.

Ruffel, S., Dussault, M. H., Palloix, A., Moury, B., Bendahmane, A., Robaglia, C., and Caranta, C. 2002. A natural recessive resistance gene against Potato virus $Y$ in pepper corresponds to the eukaryotic initiation factor 4E. Plant J. 32:1067-1075.

Saitou, N., and Nei, M. 1987. The neighbor-joining method: A new method for reconstructing phylogenetic trees. Mol. Biol. Evol. 4:406-425.

Schaad, M. C., Anderberg, R. J., and Carrington, J. C. 2000. Strain-specific interaction of the tobacco etch virus NIa protein with the translation initiation factor eIF4E in the yeast two-hybrid system. Virology 273:300-306

Schaad, M. C., and Carrington, J. C. 1996. Suppression of long-distance movement of tobacco etch virus in a nonsusceptible host. J. Virol. 70:2556-2561.

Schaad, M. C., Lellis, A. D., and Carrington, J. C. 1997. VPg of tobacco etch potyvirus is a host genotype-specific determinant for long-distance movement. J. Virol. 71:8624-8631.

Shukla, D. D., Ward, C. W., and Brunt, A. A. 1994. The Potyviridae. CAB International, Wallingford, UK.

Staswick, P., Su, W., and Howell, S. 1992. Methyl jasmonate inhibition of root growth and induction of a leaf protein are decreased in an Arabidopsis thaliana mutant. Proc. Natl. Acad. Sci. U.S.A. 89:6837-6840.

Thompson, J. D., Higgins, D. G., and Gibson, T. J. 1994. CLUSTAL W: Improving the sensitivity of progressive multiple sequence alignment through sequence weighting, position-specific gap penalties and weight matrix choice. Nucleic Acids Res. 22:4673-4680.

Voinnet, O. 2001. RNA silencing as a plant immune system against viruses. Trends Genet. 17:449-459.

Whitham, S. A., Anderberg, R. J., Chisholm, S. T., and Carrington, J. C. 2000. Arabidopsis RTM2 gene is necessary for specific restriction of tobacco etch virus and encodes an unusual small heat shock-like protein. Plant Cell 12:569-582.

Whitham, S. A., Yamamoto, M. L., and Carrington, J. C. 1999. Selectable viruses and altered susceptibility mutants in Arabidopsis thaliana. Proc. Natl. Acad. Sci. U.S.A. 96:772-777.

Wittmann, S., Chatel, H., Fortin, M. G., and Laliberte, J. F. 1997. Interaction of the viral protein genome linked of turnip mosaic potyvirus with the translational eukaryotic initiation factor (iso) 4E of Arabidopsis thaliana using the yeast two-hybrid system. Virology 234:84-92.

Yang, S. J., Revers, F., Souche, S., Lot, H., Le Gall, O., Candresse, T., and Dunez, J. 1998. Construction of full-length cDNA clones of lettuce mosaic virus (LMV) and the effects of intron-insertion on their viability in Escherichia coli and on their infectivity to plants. Arch. Virol. 143:2443-2451.

\section{AUTHOR-RECOMMENDED INTERNET RESOURCES}

Nottingham Arabidopsis Stock Centre (NASC) website: nasc.nott.ac.uk

The Arabidopsis Information Resource (TAIR): www.arabidopsis.org/ home.html

University of California-Davis Arabidopsis resistance genes webpage: niblrrs.ucdavis.edu/At_Rgenes 